\title{
Complementary and Integrative Health Practices Among Hispanics Diagnosed with Colorectal Cancer: Utilization and Communication with Physicians
}

\author{
David S. Black, PhD, MPH, ${ }^{1,2}$ Chun Nok Lam, MPH, ${ }^{1,3}$ Nathalie T. Nguyen, $\mathrm{MPH}^{1,2}$ \\ Ugonna Ihenacho, $\mathrm{MPH}^{1,2}$ and Jane C. Figueiredo, $\mathrm{PhD}^{1,2}$
}

\begin{abstract}
Objective: Complementary and integrative health $(\mathrm{CIH})$ use among Hispanic adults with colorectal cancer $(\mathrm{CRC})$ diagnosis is not well documented. Understanding the prevalence and patterns of CIH use among Hispanics offers insights to uncover potential needs for clinical services.

Design: Participants were age 21 years or older with a first-time diagnosis of CRC from population-based cancer registries in California. In-person and/or telephone-based interviews were administered to collect data on $\mathrm{CIH}$ use. Demographic and clinical diagnosis data were abstracted from medical records. Descriptive statistical and logistic regression was used to analyze the frequencies and associations between selected patient characteristics and $\mathrm{CIH}$ use.

Results: Among 631 Hispanic patients, 40.1\% reported ever using CIH. Herbal products/dietary supplements were used most often $(35.3 \%)$, followed by bodywork (16.5\%), mind-body practices $(7.8 \%)$, and homeopathy (6.7\%). About $60 \%$ of participants reported $\mathrm{CIH}$ use to address specific health conditions; however, most patients did not discuss $\mathrm{CIH}$ use with their physicians $(76.3 \%)$. Women reported higher $\mathrm{CIH}$ use than did men ( $45.1 \%$ versus $35.9 \%$; odds ratio, 1.49 [95\% confidence interval, $1.07-2.08$ ]; $p=0.02$ ). CIH use did not differ by clinical stage, time since diagnosis, or preferred language.

Conclusions: CIH use is prevalent among Hispanic patients with CRC, especially women. Little communication about $\mathrm{CIH}$ use occurs between participants and their healthcare providers. Efforts aimed at improving integrative oncology services provide an opportunity to address such gaps in healthcare service.
\end{abstract}

\section{Introduction}

C OMPLEMENTARY AND INTEGRATIVE HEALTH (CIH) approaches refer to the array of products and techniques that are used by the public outside of or alongside conventional Western medicine. According to the most recent report of the National Institutes of Health (NIH), 34\% of adults in the United States use $\mathrm{CIH}$ practices. ${ }^{1}$ Overall, this rate of use has remained stable over the past decade, while some $\mathrm{CIH}$ mind-body practices, such as meditation and yoga, have almost doubled. The U.S. public does not limit itself to conventional Western medicine and, further, does not see conventional medicine and $\mathrm{CIH}$ as mutually exclusive practices to bringing them closer to their goal for health and wellness. ${ }^{2,3}$ Therefore, CIH has major implications for U.S. public health, as users are more likely than nonusers to rate their own health as excellent and their health as better than the previous year. ${ }^{4}$

Several mind-body $\mathrm{CIH}$ approaches have an emerging evidence base suggesting their utility for ameliorating health ailments, ${ }^{5-12}$ and some natural products have also shown promise; ${ }^{13-18}$ however, methodologic and conceptual limitations do prevail in various research domains of $\mathrm{CIH},{ }^{18,19}$ and null findings are noted for some products. ${ }^{20,21}$

\footnotetext{
${ }^{1}$ Department of Preventive Medicine, Keck School of Medicine of University of Southern California, Los Angeles, CA.

${ }^{2}$ Norris Comprehensive Cancer Center, Keck School of Medicine of University of Southern California, Los Angeles, CA.

${ }^{3}$ Department of Emergency Medicine, Keck School of Medicine of University of Southern California, Los Angeles, CA.
}

(C) David S. Black et al., 2016; Published by Mary Ann Liebert, Inc. This Open Access article is distributed under the terms of the Creative Commons License (http://creativecommons.org/licenses/by/4.0), which permits unrestricted use, distribution, and reproduction in any medium, provided the original work is properly credited. 
Certain segments of the population report higher than the national average of $\mathrm{CIH}$ use. Rates of $\mathrm{CIH}$ use among individuals with chronic disease increase to over half of the population. ${ }^{22}$ This is exemplified in the population of more than 12 million people living with a cancer diagnosis, of whom $40 \%-80 \%$ report $\mathrm{CIH}$ use. ${ }^{23,24}$ Prevalence appears to increase after a cancer diagnosis and in instances of advanced cancer stage, ${ }^{25-27}$ perhaps as patients and families attempt to remediate lingering iatrogenic symptoms and improve their quality of life by less mainstream approaches. Breast cancer in women has served as the central research model for understanding CIH use and efficacy in the context of cancer, while research on other cancer types remains a relatively nascent area. Notwithstanding this limitation of cancer type and sex, integrative oncology is rapidly gaining ground in the United States, ${ }^{28}$ and clinical guidelines on the use of $\mathrm{CIH}$ approaches for patients with cancer have been provided for healthcare practitioners by the Society for Integrative Oncology. ${ }^{29,30}$

It is well known that socioeconomic status, language, and ethnicity can act as barriers to medical care access. ${ }^{31-33}$ Spanish-language preference marks a particularly vulnerable subpopulation in the United States that has less access to care $^{34}$ and is becoming a majority in several urban regions. Notable population-based differences in CIH use occur by ethnicity and socioeconomic status, wherein Hispanics report lower CIH use than whites. ${ }^{35}$ Various explanations include acculturation factors and lack of access to care. ${ }^{36-39}$ However, this might also reflect underreporting bias given that various $\mathrm{CIH}$ practices for the treatment of illness and disease are embedded within a Hispanic cultural norm that does not expound on CIH use. ${ }^{39}$ More recently, Hispanics show an increased use of certain $\mathrm{CIH}$ mind-body practices, especially yoga, which has almost doubled from $2.7 \%$ to $5.1 \%$ of the population from 2007 to 2012 (https://nccih .nih.gov/research/statistics/NHIS).

Relatively little is known about CIH use in Hispanics with a diagnosis of colorectal cancer (CRC). Existing data from several international studies show that $\mathrm{CIH}$ use among patients with CRC ranges in prevalence between $20 \%$ and $50 \% ;{ }^{27,40-42}$ however, the two U.S. studies suggest inconsistent findings, with use at $31 \%$ and $75 \% .^{43,44}$ To better understand the prevalence and patterns of $\mathrm{CIH}$ use among Hispanic patients with CRC living in the United States, this large population-based study in California sought to describe the $\mathrm{CIH}$ products and techniques used by Hispanic adults. The goal of this research is to advance knowledge on the use of $\mathrm{CIH}$ practices in diverse U.S. populations in order to inform best healthcare practices to be used with Hispanic cancer survivors.

\section{Materials and Methods}

\section{Participants and procedures}

Data were used from participants in the Hispanic Colorectal Cancer Study, which is a population-based study of individuals self-identified as Hispanic or Latino with a diagnosis of CRC. All men and women older than 21 years of age with a first time diagnosis of CRC (International Classification of Diseases for Oncology, Third Edition, codes: C18-C20) after January 2008 were eligible for participation. Cases were identified from the California Cancer Registry and/or from hospitals in Los Angeles (LAC+USC County
Hospital and USC Norris Comprehensive Cancer Center). As of September 2015, 1641 patients were recruited, of whom $633(39 \%)$ completed the psychosocial questionnaires, and $2(0.3 \%)$ patients were excluded from analysis because of missing data. All patients were post-first-line treatment and $70 \%$ had survived at least 3 years. The University of Southern California Institutional Review Board approved all study protocols.

\section{Measures}

All patients were interviewed in person or by telephone. Patient demographic information was obtained using a standardized risk factor questionnaire from the Colon Cancer Family Registry. ${ }^{19}$ The eight items measuring CIH use in the past 12 months were taken directly from the $2011 \mathrm{NIH}$ National Center for Complementary and Integrative Health survey in an effort to compare prevalence estimates from the probability sample and recent national prevalence reports published by the NIH. Cancer localization (local, regional, or distant) and first-line treatment data were obtained from the California Cancer Registry, a population-based cancer surveillance program that is part of the California Department of Public Health. Study data were collected and managed using REDCap electronic data capture tools hosted at the University of Southern California. ${ }^{45}$

\section{Statistical analysis}

Demographic characteristics for the sample were summarized using means and frequencies. Chi-square tests and $t$-tests were used as appropriate to determine statistical significance in descriptive analyses. Logistic regression was used to determine the association between patient characteristics and use of $\mathrm{CIH}$ adjusted for potential confounders. A $p$-value $<0.05$ indicated a statistically significant difference. Mean values by sex were imputed for missing data on age at the time of diagnosis for the regression models. Analyses were performed with SAS software, version 9.4 (SAS Institute Inc., Cary, NC).

\section{Results}

There were 631 (54.4\% male) patients included in the analysis; the mean age at time of diagnosis was 56.9 years (standard deviation [SD], 12.2) (Table 1). Mean time from interview to diagnosis was 3.0 years $(\mathrm{SD}, 1.2)$ and did not differ by sex. Over half of the patients were diagnosed with CRC (57.2\%) and had regional or localized disease $(89.6 \%)$. Approximately half $(50.2 \%)$ did not receive chemotherapy or radiation after diagnosis.

More than a third of the study population reported using at least one form of $\mathrm{CIH}(40.1 \%)$ (Table 2). Overall, herbal products and dietary supplements were the most commonly used $\mathrm{CIH}$ approach in the past 12 months (35.3\%), followed by bodywork (16.5\%), mind-body practices $(7.8 \%)$, and homeopathy $(6.7 \%)$. Among the $\mathrm{CIH}$ users, most reported use to target a specific health condition $(59.3 \%)$, to prevent disease and promote overall wellness $(59.8 \%)$, or to ameliorate painful conditions (43.4\%). Only $23.7 \%$ of the patients had discussed $\mathrm{CIH}$ with their physicians. Some individuals reported discussing $\mathrm{CIH}$ use with a nurse or nurse practitioner $(8.5 \%)$, pharmacist $(2.1 \%)$, physician's assistant (4.5\%), and other healthcare provider $(2.2 \%)$ (data not shown). The most highly 
Table 1. Characteristics of Participants in the Hispanic Colorectal Cancer Study

\begin{tabular}{|c|c|}
\hline Variable & Value $(\mathrm{n}=631)$ \\
\hline $\begin{array}{l}\text { Age }(y r) \\
\text { Age at diagnosis }(y r) \\
\text { Missing }\end{array}$ & $\begin{array}{c}59.5 \pm 12.3 \\
56.9 \pm 12.2 \\
82\end{array}$ \\
\hline $\begin{array}{l}\text { Sex } \\
\quad \text { Male } \\
\text { Female }\end{array}$ & $\begin{array}{l}344(54.4) \\
287(45.6)\end{array}$ \\
\hline $\begin{array}{l}\text { Income } \\
\quad<\$ 15,000 \\
\$ 15,000-\$ 29,000 \\
\$ 30,000-\$ 44,000 \\
\$ 45,000-\$ 69,000 \\
\geq \$ 70,000 \\
\text { Missing }\end{array}$ & $\begin{array}{l}118(22.3) \\
152(28.7) \\
82(15.5) \\
81(15.3) \\
96(18.2) \\
102\end{array}$ \\
\hline $\begin{array}{l}\text { Preferred language } \\
\text { English } \\
\text { Spanish }\end{array}$ & $\begin{array}{l}296(46.9) \\
335(53.1)\end{array}$ \\
\hline $\begin{array}{l}\text { Cancer site } \\
\text { Colon } \\
\text { Rectum } \\
\text { Missing }\end{array}$ & $\begin{array}{c}314(57.2) \\
235(42.8) \\
82\end{array}$ \\
\hline $\begin{array}{l}\text { Treatment } \\
\text { No chemotherapy/radiation } \\
\text { Chemotherapy only } \\
\text { Chemotherapy and radiation } \\
\text { Radiation only } \\
\text { Missing }\end{array}$ & $\begin{array}{c}265(50.2) \\
135(25.6) \\
124(23.5) \\
4(0.8) \\
103\end{array}$ \\
\hline $\begin{array}{l}\text { Clinical stage } \\
\text { Localized } \\
\text { Regional } \\
\text { Remote } \\
\text { Missing }\end{array}$ & $\begin{array}{c}211(40.8) \\
252(48.7) \\
54(10.4) \\
114\end{array}$ \\
\hline $\begin{array}{l}\text { Time since diagnosis } \\
\quad \geq 3 \mathrm{yr} \\
<3 \mathrm{yr} \\
\text { Missing }\end{array}$ & $\begin{array}{c}384(70.0) \\
165(30.1) \\
82\end{array}$ \\
\hline $\begin{array}{l}\text { History of polyps } \\
\text { Don't know/missing }\end{array}$ & $\begin{array}{c}33(53.8) \\
16\end{array}$ \\
\hline $\begin{array}{l}\text { Reason for first colonoscopy } \\
\text { Investigate new problem } \\
\text { Family history of CRC } \\
\text { Routine/yearly check-up } \\
\text { Follow-up previous problem } \\
\text { Follow-up of fecal blood test } \\
\text { Other }\end{array}$ & $\begin{aligned} 366 & (58.0) \\
20 & (3.2) \\
127 & (20.1) \\
78 & (12.4) \\
38 & (6.0) \\
60 & (9.5)\end{aligned}$ \\
\hline
\end{tabular}

Values are expressed as $n(\%)$ or mean \pm standard deviation. $\mathrm{CRC}$, colorectal cancer.

reported reason for not discussing $\mathrm{CIH}$ with a healthcare provider was lack of knowledge to report (25.6\%). Overall, family or friends were the most frequent source of $\mathrm{CIH}$ information (26.9\%), followed by radio/TV (7.7\%) and the Internet (7.5\%).

In Table 3, sex was the only patient characteristic associated with $\mathrm{CIH}$ use after adjusting for other covariates (women, $45.1 \%$; men, $35.9 \%$ ). Overall, women were nearly $50 \%$ more likely to have ever used one or more forms of CIH compared to men (multivariable-adjusted odds ratio, $1.49 ; 95 \%$ confidence interval, 1.07-2.08). Other patient characteristics, including age, cancer stage, time since di-
Table 2. Complementary and Integrative Health Use Among Participants in the Hispanic Colorectal Cancer Study

\begin{tabular}{|c|c|}
\hline Variable & $\begin{array}{c}\mathrm{N}=631 \\
(\%)\end{array}$ \\
\hline Ever use of CIH & $253(40.1)$ \\
\hline Past 12 mo use among users & \\
\hline Herbal products and dietary supplements & $222(35.3)$ \\
\hline Bodywork & $104(16.5)$ \\
\hline Mind-body practices & $49(7.8)$ \\
\hline Homeopathy & $42(6.7)$ \\
\hline Other & $24(3.9)$ \\
\hline
\end{tabular}

Reasons for $\mathrm{CIH}$ use among users

Specific health condition 147 (59.3)

Prevention/overall wellness $147(59.8)$

Painful conditions 108 (43.4)

Supplement conventional medicine $\quad 93(37.7)$

Other reason 14 (5.8)

Reasons CIH use was not discussed with health provider

Didn't know you should 149 (25.6)

Healthcare provider never asked $142(24.1)$

Not enough time during office visit 72 (12.3)

Didn't think healthcare provider knows about 55 (9.4)

the topic

Weren't comfortable discussing it with your $51(8.7)$

healthcare provider

Healthcare provider would have been $53(9.1)$

dismissive or told you not to do it

Other reason

$88(14.8)$

Primary source of $\mathrm{CIH}$ information among users

Family/friend

$157(26.9)$

Internet

Radio/TV

$44(7.5)$

$45(7.7)$

Physician

$34(5.8)$

Publications $10(1.7)$

Nutritionist $6(1.0)$

Physician assistant $2(0.3)$

Pharmacist $2(0.3)$

Health food stores $3(0.5)$

Other 6 (1.0)

No CIH information source 273 (46.8)

Proportions may vary slightly due to missing values.

$\mathrm{CIH}$, complementary and integrative health.

agnosis, treatment, and preferred language, were not associated with $\mathrm{CIH}$ use.

\section{Discussion}

To better understand the prevalence and patterns of $\mathrm{CIH}$ use among Hispanic patients with CRC living in the United States, this study assessed the $\mathrm{CIH}$ products and techniques used by Hispanic adults in a large population-based study in California. Results showed that $\mathrm{CIH}$ use is prevalent in this population, in lieu of possible underreporting bias in Hispanics. ${ }^{39}$ Women were more likely than men to use herbal products and dietary supplements, mind-body practices, and homeopathy in the past 12 months. Use of $\mathrm{CIH}$ was not dependent on clinical stage of cancer, time since diagnosis, or preferred language, suggesting that disease-specific and acculturation factors have minimal confounding effects on 
Table 3. Association Between Patient Characteristics and Ever Use of CiH

\begin{tabular}{|c|c|c|c|c|}
\hline Variable & Crude OR $(95 \%$ CI $)$ & $\mathrm{p}$-Value & Adjusted OR $(95 \% C I)^{\mathrm{a}}$ & $\mathrm{p}$-Value \\
\hline \multicolumn{5}{|l|}{ Age at diagnosis ${ }^{b}$} \\
\hline Age $\geq 50 \mathrm{yr}$ & 1 & & 1 & \\
\hline Age $<50 \mathrm{yr}$ & $1.32(0.90-1.95)$ & 0.16 & $1.14(0.76-1.71)$ & 0.53 \\
\hline \multicolumn{5}{|l|}{ Sex } \\
\hline Male & 1 & & 1 & \\
\hline Female & $1.47(1.07-2.03)$ & 0.02 & $1.49(1.07-2.08)$ & 0.02 \\
\hline \multicolumn{5}{|l|}{ Language } \\
\hline English & 1 & & 1 & \\
\hline Spanish & $0.70(0.51-0.97)$ & 0.03 & $0.90(0.60-1.44)$ & 0.60 \\
\hline \multicolumn{5}{|l|}{ Time since diagnosis } \\
\hline$\geq 3 \mathrm{yr}$ & 1 & & 1 & \\
\hline$<3 \mathrm{yr}$ & $1.05(0.72-1.52)$ & 0.80 & $1.03(0.70-1.52)$ & 0.87 \\
\hline \multicolumn{5}{|l|}{ Tumor localization } \\
\hline Local & 1 & & 1 & \\
\hline Regional & $0.73(0.50-1.06)$ & 0.10 & $0.75(0.51-1.10)$ & 0.14 \\
\hline Remote & $1.29(0.71-2.35)$ & 0.40 & $1.16(0.62-2.16)$ & 0.64 \\
\hline \multicolumn{5}{|l|}{ Cancer treatment } \\
\hline No chemotherapy or radiation & 1 & & 1 & \\
\hline Chemotherapy and/or radiation & $0.89(0.63-1.26)$ & 0.53 & $0.87(0.60-1.25)$ & 0.45 \\
\hline
\end{tabular}

the explanation for $\mathrm{CIH}$ use in this population. Most $\mathrm{CIH}$ users reported using $\mathrm{CIH}$ to alleviate specific health conditions and for purposes of wellness, indicating active participation from survivors to enhance their quality of life during treatment and/or survivorship stages. ${ }^{46}$ The prevailing use of $\mathrm{CIH}$ in the Hispanic population suggests that the broader movement of integrative oncology care is in need for the less-studied minority populations. ${ }^{29,30,47}$

The prevalence of $\mathrm{CIH}$ use among Hispanic cancer survivors observed in this population-based study (41\%) falls within the range $(40 \%-80 \%)$ of patients living with cancer, and CRC specifically (20\%-50\%) when considering international data; ${ }^{27,40-42}$ it is higher than the national average of CIH among all adults (34\%). ${ }^{23,24}$ When compared with the prevalence of $\mathrm{CIH}$ use among Hispanics living without cancer $(50 \%-90 \%),{ }^{39,48}$ the current findings suggested a lower rate of use. A possible explanation is that previous studies often measured $\mathrm{CIH}$ use with measurement indicators specific to the Hispanic population/culture and therefore were more sensitive to positive reporting. Although the $\mathrm{NIH}$-based measurement of $\mathrm{CIH}$ use applied in this study may be less sensitive for capturing Hispanic-specific $\mathrm{CIH}$ use, the results still suggest that many Hispanic patients with cancer practice $\mathrm{CIH}$ alongside conventional care options as a goal to pursue health and wellness. ${ }^{2,3}$

Because few studies have focused on CIH use in minority populations with more aggressive forms of cancer, such as with the case of CRC, these results call for the further study of the safety and effectiveness of $\mathrm{CIH}$ products and services that are already used in the daily life of cancer patients and survivors from diverse race/ethnic backgrounds and cancer types. ${ }^{49}$ Our observation of higher $\mathrm{CIH}$ use among women than men also aligns with previous literature. ${ }^{50-52}$ Studies have suggested that women may have greater awareness and access to $\mathrm{CIH}$ resources because of their nurturing roles in the family and greater value on health practices in general. ${ }^{53-55}$ Healthcare professionals and oncology services can be made aware of possible differences in $\mathrm{CIH}$ disclosure behaviors and preferences between men and women when planning for their care.

Patient-care provider communication on $\mathrm{CIH}$ use was lacking among the study participants. Recent professional efforts aimed at improving integrative oncology services provide an opportunity to address such gaps in healthcare service. ${ }^{56,57}$ Leading cancer institutes incorporate $\mathrm{CIH}$ and supportive care information via their websites for patient and family education. ${ }^{56,57}$ This is important because cancer patients and survivors often do not communicate about their current $\mathrm{CIH}$ practices due to fear and anticipation of negative responses from a physician, a perception that $\mathrm{CIH}$ is irrelevant to the conventional medical treatment, and a sense that the medical professional is unwilling to contribute useful information about CIH practices. ${ }^{58,59}$ Poor communication about $\mathrm{CIH}$ use in this manner has the potential to create several medical care problems, such as supplementdrug interactions. ${ }^{60-62}$ Improved provider-initiated communication about $\mathrm{CIH}$ has implications for reducing such errors and addressing the varied needs of minority patients. As specific $\mathrm{CIH}$ products and techniques gain scientific backing or are found to be ineffective, healthcare providers will likely serve as the major channel of monitoring, communication, and referral for correct $\mathrm{CIH}$ use. .,63,64 $^{\text {. }}$

The primary source of $\mathrm{CIH}$ information among Hispanic patients with CRC in this study was family or friends. These individuals have a major influence on the cancer patient's navigation of information and decision making ${ }^{64}$ and might be considered for inclusion in health communication messages so that they can make evidence-based recommendations that do not increase health risks in the survivor. Television, radio, and Internet were other major sources of 
CIH information for study participants. ${ }^{65}$ Increasingly, patients with cancer are relying on mass media messages for health and wellness recommendations; however, the quality and validity of the $\mathrm{CIH}$ information from these sources can be conflicting and unfounded. ${ }^{57,65-67}$ From a public health standpoint, these commonly accessed communication channels can be used to relay effective health messages about $\mathrm{CIH}$ use and safety.

The results reflected in this report have some limitations. The study used a single questionnaire as part of an ongoing population-based study. Responses depended on participants' recall of $\mathrm{CIH}$ use in the past 12 months, as well as their willingness to report their use accurately. The $\mathrm{CIH}$ items used failed to capture some culturally specific traditional practices, such as visiting a curandero or healer, and the language developed by the NIH for the CIH survey items might not be commensurate with cultural terms used to describe similar practices. Considering these limitations, this study provided one of the first descriptions of CIH use among a representative sample of Hispanics at various stages of CRC disease and survivorship. Future possible lines of investigation include discerning the reasons for lack of communication about $\mathrm{CIH}$ use between the study population and healthcare providers, as well as developing approaches to overcome barriers to improve communication in cancer care.

In conclusion, this study provides descriptive information about the use of $\mathrm{CIH}$ among Hispanic adults with a CRC diagnosis. Findings indicate that $\mathrm{CIH}$ use is common in this population, especially among women, but patient-provider communication about such practices is greatly lacking, presumably because of patient misperceptions surrounding conventional medicine practices. Understanding the $\mathrm{CIH}$ preferences and practices of underrepresented minority populations can improve communication between providers and patients as well as assist in the creation of culturally adapted health communication messages intended for cancer survivors.

\section{Acknowledgments}

Funding source: Support from the USC/UCLA Center on Biodemography and Population Health NIH National Institute on Aging grant (P30AG017265 to D.S.B.) and the NIH National Cancer Institute (RO1CA155101 to J.C.F.). The collection of cancer incidence data used in this study was supported by the California Department of Public Health as part of the statewide cancer reporting program mandated by California Health and Safety Code Section 103885; the National Cancer Institute's Surveillance, Epidemiology and End Results Program under contract HHSN261201000140C awarded to the Cancer Prevention Institute of California, contract HHSN261201000035C awarded to the University of Southern California, and contract HHSN261201000034C awarded to the Public Health Institute; and the Centers for Disease Control and Prevention's National Program of Cancer Registries, under agreement U58DP003862-01 awarded to the California Department of Public Health. The ideas and opinions expressed herein are those of the author(s) and endorsement by the State of California, Department of Public Health, the National Cancer Institute, and the Centers for Disease
Control and Prevention or their contractors and subcontractors is not intended nor should be inferred.

The authors are indebted to the individuals who participated in this study. They thank the following individuals for their assistance with logistic support and management, interviewing patients, and data entry: Julissa Ramirez, Yaquelin Perez, Daniel Collin, Alicia Rivera, Lauren Gerstmann, and the student intern staff.

\section{Author Disclosure Statement}

No competing financial interests exist.

\section{References}

1. Clarke T, Black L, Stussman B, Barnes P, Nahin R. Trends in the use of complementary health approaches among adults: United States, 2002-201 2. National health statistics reports: Hyattsville, MD: National Center for Health Statistics; 2015.

2. Astin JA. Why patients use alternative medicine: results of a national study. JAMA 1998;279:1548-1553.

3. Druss BG, Rosenheck RA. Association between use of unconventional therapies and conventional medical services. JAMA 1999;282:651-656.

4. Nguyen LT, Davis RB, Kaptchuk TJ, Phillips RS. Use of complementary and alternative medicine and self-rated health status: results from a national survey. J Gen Intern Med. 2011;26:399-404.

5. Goyal M, Singh S, Sibinga EM, et al. Meditation programs for psychological stress and well-being: a systematic review and meta-analysis. JAMA Intern Med. 2014;174:357368.

6. Kumar S, Beaton K, Hughes T. The effectiveness of massage therapy for the treatment of nonspecific low back pain: a systematic review of systematic reviews. Int $\mathbf{J}$ Gen Med 2013;6:733-741.

7. Borge CR, Mengshoel AM, Omenaas E, et al. Effects of guided deep breathing on breathlessness and the breathing pattern in chronic obstructive pulmonary disease: a doubleblind randomized control study. Patient Educ Counsel 2015;98:182-190.

8. Black DS, O'Reilly GA, Olmstead R, Breen EC, Irwin MR. Mindfulness meditation and improvement in sleep quality and daytime impairment among older adults with sleep disturbances: a randomized clinical trial. JAMA Intern Med. 2015;175:494-501.

9. O'Reilly GA, Cook L, Spruijt-Metz D, Black DS. Mindfulness-based interventions for obesity-related eating behaviours: a literature review. Obes Rev 2014;15:453461.

10. Black DS, Irwin MR, Olmstead R, Ji E, Crabb Breen E, Motivala SJ. Tai chi meditation effects on nuclear factorkappaB signaling in lonely older adults: a randomized controlled trial. Psychother Psychosom 2014;83:315-317.

11. SeyedAlinaghi S, Jam S, Foroughi M, et al. Randomized controlled trial of mindfulness-based stress reduction delivered to human immunodeficiency virus-positive patients in Iran: effects on CD4(+) T lymphocyte count and medical and psychological symptoms. Psychosom Med 2012;74: 620-627.

12. Black DS. Mindfulness-based interventions: an antidote to suffering in the context of substance use, misuse, and addiction. Substance Use Misuse 2014;49:487-491. 
13. Wang C, Harris WS, Chung M, et al. n-3 Fatty acids from fish or fish-oil supplements, but not alpha-linolenic acid, benefit cardiovascular disease outcomes in primary- and secondary-prevention studies: a systematic review. Am J Clin Nutr 2006;84:5-17.

14. Wang L, Manson JE, Song Y, Sesso HD. Systematic review: vitamin $\mathrm{D}$ and calcium supplementation in prevention of cardiovascular events. Ann Intern Med 2010;152: 315-323.

15. Hempel S, Newberry SJ, Maher AR, et al. Probiotics for the prevention and treatment of antibiotic-associated diarrhea: a systematic review and meta-analysis. JAMA 2012;307: 1959-1969.

16. Huxley R, Lee CM, Barzi F, et al. Coffee, decaffeinated coffee, and tea consumption in relation to incident type 2 diabetes mellitus: a systematic review with meta-analysis. Arch Intern Med 2009;169:2053-2063.

17. Kim A, Chiu A, Barone MK, et al. Green tea catechins decrease total and low-density lipoprotein cholesterol: a systematic review and meta-analysis. J Am Diet Assoc 2011;111:1720-1729.

18. Coulter ID, Khorsan R, Crawford C, Hsiao AF. Integrative health care under review: an emerging field. J Manip Physiolog Therap 2010;33:690-710.

19. Jonas WB. Building an evidence house: challenges and solutions to research in complementary and alternative medicine. Forsch Komplementarmed Klass Naturheilkd 2005;12:159-167.

20. MacLean CH, Newberry SJ, Mojica WA, et al. Effects of omega-3 fatty acids on cancer risk: a systematic review. JAMA. 2006;295:403-415.

21. Buscemi N, Vandermeer B, Hooton N, et al. Efficacy and safety of exogenous melatonin for secondary sleep disorders and sleep disorders accompanying sleep restriction: meta-analysis. BMJ. 2006;332:385-393.

22. Saydah SH, Eberhardt MS. Use of complementary and alternative medicine among adults with chronic diseases: United States 2002. J Altern Complement Med 2006;12: 805-812.

23. Horneber M, Bueschel G, Dennert G, Less D, Ritter E, Zwahlen M. How many cancer patients use complementary and alternative medicine: a systematic review and metaanalysis. Integr Cancer Ther 2012;11:187-203.

24. Boon H, Stewart M, Kennard MA, et al. Use of complementary/alternative medicine by breast cancer survivors in Ontario: prevalence and perceptions. J Clin Oncol 2000;18: 2515-2521.

25. Paul M, Davey B, Senf B, et al. Patients with advanced cancer and their usage of complementary and alternative medicine. J Cancer Res Clin Oncol 2013;139:1515-1522.

26. Greenlee H, Kwan ML, Ergas IJ, et al. Complementary and alternative therapy use before and after breast cancer diagnosis: the Pathways Study. Breast Cancer Res Treat 2009; 117:653-665.

27. Molassiotis A, Fernandez-Ortega P, Pud D, et al. Complementary and alternative medicine use in colorectal cancer patients in seven European countries. Complement Ther Med 2005;13:251-257.

28. Kligler B, Chesney M. Academic health centers and the growth of integrative medicine. J Natl Cancer Inst Monogr2014;2014: 292-293.

29. Greenlee H, Balneaves LG, Carlson LE, et al. Clinical practice guidelines on the use of integrative therapies as supportive care in patients treated for breast cancer. J Natl Cancer Inst Monogr. 2014;2014:346-358.
30. Deng GE, Frenkel M, Cohen L, et al. Evidence-based clinical practice guidelines for integrative oncology: complementary therapies and botanicals. J SocIntegr Oncol 2009;7:85.

31. Hayward RA, Shapiro MF, Freeman HE, Corey CR. Inequities in health services among insured Americans. Do working-age adults have less access to medical care than the elderly? N Engl J Med 1988;318:1507-1512.

32. Schneider EC, Zaslavsky AM, Epstein AM. Racial disparities in the quality of care for enrollees in medicare managed care. JAMA 2002;287:1288-1294.

33. Fiscella K, Franks P, Gold MR, Clancy CM. Inequality in quality: addressing socioeconomic, racial, and ethnic disparities in health care. JAMA 2000;283:2579-2584.

34. DuBard CA, Gizlice Z. Language spoken and differences in health status, access to care, and receipt of preventive services among US Hispanics. Am J Public Health 2008;98: 2021-2028.

35. Olano HA, Kachan D, Tannenbaum SL, Mehta A, Annane D, Lee DJ. Engagement in mindfulness practices by U.S. adults: sociodemographic barriers. J Altern Complement Med. 2015;21:100-102.

36. Martin BI, Gerkovich MM, Deyo RA, et al. The association of complementary and alternative medicine use and health care expenditures for back and neck problems. Med Care 2012;50:1029-1036.

37. Su D, Li L, Pagan JA. Acculturation and the use of complementary and alternative medicine. Soc Sci Med 2008; 66:439-453.

38. Hawk C, Ndetan H, Evans MW Jr. Potential role of complementary and alternative health care providers in chronic disease prevention and health promotion: an analysis of National Health Interview Survey data. Prev Med 2012;54:18-22.

39. Ortiz BI, Shields KM, Clauson KA, Clay PG. Complementary and alternative medicine use among Hispanics in the United States. Ann Pharmacother. 2007;41:994-1004.

40. Nissen N, Lunde A, Pedersen CG, Johannessen H. The use of complementary and alternative medicine after the completion of hospital treatment for colorectal cancer: findings from a questionnaire study in Denmark. BMC Complement Altern Med 2014;14:388.

41. Pu CY, Lan VM, Lan CF, Lang HC. The determinants of traditional Chinese medicine and acupuncture utilization for cancer patients with simultaneous conventional treatment. Eur J Cancer Care 2008;17:340-349.

42. Tsai SJ, Ruan YX, Lee CC, et al. Use of Chinese medicine among colorectal cancer patients: a nationwide populationbased study. Afr J Trad Complement Altern Med 2014; 11:343-349.

43. Sohl SJ, Borowski LA, Kent EE, et al. Cancer survivors' disclosure of complementary health approaches to physicians: the role of patient-centered communication. Cancer 2015;121:900-907.

44. Lawsin C, DuHamel K, Itzkowitz SH, et al. Demographic, medical, and psychosocial correlates to CAM use among survivors of colorectal cancer. Support Care Cancer 2007; 15:557-564.

45. Harris PA, Taylor R, Thielke R, Payne J, Gonzalez N, Conde JG. Research Electronic Data Capture (REDCap) a metadata-driven methodology and workflow process for providing translational research informatics support. J Biomed Informat 2009;42:377-381.

46. Ernst E, Lee MS. Acupuncture for palliative and supportive cancer care: a systematic review of systematic reviews. J Pain Symptom Manage 2010;40:e3-e5. 
47. Kushi LH, Doyle C, McCullough M, et al. American Cancer Society guidelines on nutrition and physical activity for cancer prevention. CA Cancer J Clin 2012;62:30-67.

48. Owens B, Jackson M, Berndt A. Complementary therapy used by Hispanic women during treatment for breast cancer. J Holist Nurs 2009;27:167-176.

49. Sewitch MJ, Rajput Y. A literature review of complementary and alternative medicine use by colorectal cancer patients. Complement Ther Clin Pract 2010;16:52-56.

50. Bishop FL, Lewith GT. Who uses CAM? A narrative review of demographic characteristics and health factors associated with CAM use. Evid Based Complement Alternat Med 2010;7:11-28.

51. Kristoffersen AE, Stub T, Salamonsen A, Musial F, Hamberg K. Gender differences in prevalence and associations for use of CAM in a large population study. BMC Complement Altern Med 2014;14:463.

52. Mackenzie ER, Taylor L, Bloom BS, Hufford DJ, Johnson JC. Ethnic minority use of complementary and alternative medicine (CAM): a national probability survey of CAM utilizers. Altern Ther Health Med 2003;9:50-56.

53. Daykin N, Naidoo J. Feminist critiques of health promotion. In: Bunton R., Nettleton S, Burrows R, eds. Towards a Sociology of Health Promotion. London: Routledge, 1995:57.

54. Pollard TM, Steptoe A, Wardle J. Motives underlying healthy eating: using the Food Choice Questionnaire to explain variation in dietary intake. J Biosoc Sci 1998;30:165-179.

55. Scambler G. Sociology as Applied to Medicine. Elsevier Health Sciences, 2008.

56. Mao JJ, Palmer CS, Healy KE, Desai K, Amsterdam J. Complementary and alternative medicine use among cancer survivors: a population-based study. J Cancer Survivorship 2011;5:8-17.

57. Brauer JA, El Sehamy A, Metz JM, Mao JJ. Complementary and alternative medicine and supportive care at leading cancer centers: a systematic analysis of websites. J Altern Complement Med 2010;16:183-186.

58. Adler SR. Complementary and alternative medicine use among women with breast cancer. Med Anthropol Q. 1999;13:214-222.
59. Lam CN, Terp S, Lee MM. Use of Chinese medicine among foreign-born Chinese residents of San Francisco. Chin J Integr Med 2014;1-6.

60. Bressler R. Herb-drug interactions: interactions between Ginkgo biloba and prescription medications. Geriatrics 2005;6030-33.

61. Moses GM, McGuire TM. Drug interactions with complementary medicines. Aust Prescr. 2010;33:177-180.

62. Niggemann B, Grüber C. Side-effects of complementary and alternative medicine. Allergy. 2003;58:707-716.

63. Black D, Greeson L. Mindfulness-based interventions in routine clinical care for stress related ailments: Comment. JAMA Intern Med 2014;174:357-358.

64. Siminoff LA, Zyzanski SJ, Rose JH, Zhang AY. The Cancer Communication Assessment Tool for Patients and Families (CCAT-PF): a new measure. Psychooncology 2008; 17:1216-1224.

65. Weeks LC, Strudsholm T. A scoping review of research on complementary and alternative medicine (CAM) and the mass media: looking back, moving forward. BMC Complement Altern Med 2008;8:43.

66. Matthews SC, Camacho A, Mills PJ, Dimsdale JE. The internet for medical information about cancer: help or hindrance? Psychosomatics 2003;44:100-103.

67. Lewis N, Gray SW, Freres DR, Hornik RC. Examining cross-source engagement with cancer-related information and its impact on doctor-patient relations. Health Commun 2009;24:723-734.

Address correspondence to:

Jane C. Figueiredo, PhD

Keck School of Medicine

University of Southern California

Harlyne Norris Cancer Research Tower

1450 Biggy Street

Room 1509J

Los Angeles, CA 90089

E-mail: janefigu@usc.edu 